\title{
Concerning Mind
}

\author{
C. Miller Fisher
}

\begin{abstract}
The nature of the human mind is addressed from a neurological viewpoint. First from reported observations on subjects born blind with congenital cataract, who acquired vision after surgery, the concept of the primacy of somatosensation is developed. Therefrom some principles of the organization of higher sensory functions in the dominant parietal, occipital and temporal lobes are deduced. Sentience is traced to somatosensation. Some characteristics of the mind and of thinking are described. The non-existence of the unconscious is inferred. The question of free will is approached. Using neurological experience it is demonstrated that a good case for operation of a free will is difficult to establish. Positing the absence of a free will may be beneficial in the analysis and management of behavior. Finally the opportunity to study the nature and mechanism of the emotions in clinical neurology is outlined.
\end{abstract}

RÉSUMÉ: À propos de l'intellect. Nous considérons la nature de l'intellect humain d'un point de vue neurologique. Nous développons d'abord le concept de la primauté somesthésique en nous basant sur les observations de sujets atteints de cécité congénitale due à des cataractes, qui ont acquis la vision après la chirurgie. Nous en déduisons des principes de l'organisation des fonctions sensitives supérieures dans le lobe pariétal, occipital et temporal dominant. Nous relions la perception sensitive à la somesthésie. Certaines caractéristiques de l'intellect et de la pensée sont décrites. Nous en déduisons l'inexistence de l'inconscient. La question du libre arbitre est abordée. Nous démontrons, à partir de l'expérience neurologique, qu'il est difficile de justifier l'existence du libre arbitre. Il pourrait être bénéfique dans l'analyse et la modification du comportement de proposer l'absence de libre arbitre. Nous indiquons finalement la possibilité d'étudier la nature et les mécanismes des émotions en neurologie clinique.

Can. J. Neurol. Sci. 1993; 20: 247-253

Observations on the nature of the human mind stem from several disciplines-psychology, philosophy, neuroanatomy, neurophysiology, neuro-imaging, psychiatry and neurology. In 1872 Hughlings Jackson wrote "Medical men since they only, witness the results of the experiments of disease on the nervous system of man, will be looked to more and more for facts bearing on the physiology of the mind".'

Neurologists with their knowledge of a) the anatomy, physiology and pathology of the human nervous system, b) the cerebral localization of neurological function, and c) the disturbances of behavior caused by disease, should be in as good a position as any neuroscientist to have an opinion concerning any principles or rules governing human mentation. The observations to be described here are based on clinical experience and have seemed to be useful in the interpretation of clinical events. Nevertheless they may be erroneous for it is difficult or impossible to prove any tenet relating to the mind.

My remarks are but a mere appendix to the ideas of countless scholars who through the ages have pondered upon the same fundamental enigmas of human existence. If there be anything original it will derive from evidence that clinical experience has yielded.

\section{Persons Born Blind Who Later Acquired Vision}

An experiment of nature that may contribute information about the highest integrative action of the nervous system was provided in the experiences of persons who were born blind because of bilateral congenital cataracts, and who acquired vision for the first time when the cataracts were surgically treated later in life, between the ages of seven and 46 years. These patients became able to see for the first time at a period in life when the nervous system was more or less mature and the perceptual experience enjoyed through the other sensory modalities had reached a relatively high degree of complexity. ${ }^{2}$

The first medically reported case was that of Cheselden in London in 1728. von Senden ${ }^{2}$ listed 66 cases from the literature in the 200 years up to 1931. In more recent years congenital cataract has been treated early in life when mental development is limited and testing is uninformative. The following description summarizes observations made in these cases as a group and which need not apply in any given case.

Before surgery all subjects could see bright light. Color discrimination varied but nearly all subjects could identify some colors if they were in bright light and close up. A few patients 
could appreciate direction. In no case was the form of objects appreciated visually. All patients were raised blind and some read braille. Patients were usually of adequate intelligence to validate their observations.

Immediately after removal of the cataract from one eye the subjects far from seeing and recognizing the world around them comprehended very little. Some were unaware that they saw; one said the brightness or what he sensed touched his eye, touch having been the only word he had ever known to describe contact. To develop useful vision often required concentrated tedious practicing for days, weeks and months.

Initially the subjects were unable to visually recognize or name common objects they were familiar with and promptly recognized through the sense of touch, e.g., knife, fork, spoon, cup, key, hat, handkerchief, watch, egg, scissors, dog, etc. They first saw colored areas or patches, later outlines, borders or edges. Although visual acuity was deemed adequate there was difficulty in distinguishing different shapes such as square, circle and triangle. Once these could be identified as white cardboard cutouts, they were no longer recognized if they were colored. Once identified as colored cutouts, they were no longer recognized when suspended by a thread, or placed vertically instead of lying on a surface or if similar shapes were made from wire outlines or drawn on a sheet of paper. A square was identified by counting the four corners or angles; a circle had no corners. Three dimensional forms could not be distinguished from two dimensional. A white cardboard oval did not differ from an egg.

Movements of an object could not be appreciated. There was an inability to tell direction, distance, size, length, horizontal from vertical, near from far and larger from smaller. Subjects made gross errors in reaching for objects or utensils. A face was at first featureless. With experience the eyes, nose, mouth or ears might be seen individually but not recognized as a whole. The family dog might be mistaken for the cat until patted. There was particular difficulty in interpreting pictures and photographs where perspective and shadow were important. It was difficult for subjects to comprehend that a person or object could vary in size in different picture. The puzzling reactions of subjects seeing their hands and touching themselves in front of a mirror were commented on. The ability to discriminate shades and brightness of colors remained impaired. In this list of abnormalities one recognizes virtually every disorder of higher visual function encountered in disease processes in clinical neurology. ${ }^{3}$

In many instances the patients finally adopted the newly acquired life of vision and gave up the customs of their old blindness.

\section{The Primacy of Somatosensation}

Judging from these observations the higher visual function of humans does not exist innately but is gradually developed probably through early-life experience under normal circumstances. Light stimuli by themselves, that is patterns of brightness and color cannot reflect external reality. It might be postulated that concomitant association with the other sensory modalities, particularly, as in these subjects, somatosensation, especially touch and proprioception, is required in order that the spatial dimension of vision be created. According to von Senden who was greatly interested in the concept of space and form in the blind, the somatosensory experience of the blind had provided no preparation for any aspect of vision. Every element of visionangle, direction, outline, shape, form, motion, distance, perspective, shadow, etc derived its "meaning" or imagery from visualsomatosensory concurrence. To "see" what we look at requires the visual system plus the parietal lobes.

It must be asked however whether the observations in these patients are physiologically sound enough to justify the foregoing inferences. It is not unlikely that through lack of early life complex visual input, the patient's visual cortical system failed to develop normally ${ }^{4}$ akin to events in experimental newborn animals raised in the dark. Some of the visual system may have been appropriated by somatosensory activity. In spite of these not insubstantial limitations it is possible that the manner of acquisition of vision in these cases provides some information about the normal development of visual function in early life. Such a claim would be bolstered had a much more detailed serial examination of vision been made during the period of improvement.

Assuming that normally vision does acquire its full imagery only through its "association" with somatosensation, it would follow that somatosensation must be the basic sensory modality. Somatic sensation is immediate, of the body, highly localized and real. We are touched and we touch. The vast sensory covering of the organism along with its proprioceptive and visceral components defines the organism. Color and sound originating at a distance are secondary additions. If this concept of the primacy of somatosensation were true, it would provide a mechanism for integrating vision and audition into the nervous system proper of the organism, the tangible I or me, rather than having them separately appended.

After developing the above thesis my attention was drawn to the fact that 200 years ago, Diderot ${ }^{5}$ and Condillac $^{6}$ had recognized that the basic source of information about the external world is the sense of touch. Interestingly, their views were also based on the results of the removal of congenital cataracts, namely in Cheselden's original case, the details of which were mentioned by both authors. The possible importance of touch in tying sensory data to the soma was not formulated.

At this juncture, it might be asked if a "purely" somesthetic mind might exist, devoid of visual and auditory content. Indeed the mental life of Helen Keller was so constituted prior to her instruction by Anne Sullivan. "I did not know that I knew aught or that I lived or acted or desired. I had neither will nor intellect. I was carried along to objects and acts by a certain blind animal impetus. I had a mind which caused me to feel anger and satisfaction. I never viewed anything beforehand or chose it. Nonfamily members regarded me as an idiot."7 Before her "soul's sudden waking from silence and darkness" she knew the fragrance of honeysuckle, the perfume of wild grapes, the first violets and lilies. Her hands felt everything and the movements made by things. She felt leaves and blossoms. Her memory was tactile. She felt the sun on her face. She had a playmate and knew affection, sentiment and tenderness. Then one day as Anne Sullivan drew on her palm, Helen Keller's mind was created in a period of a few hours when she realized that everything had a name and symbols stood for things.

\section{Generalization}

Can what has been said about vision be extrapolated to the more general organization of brain function? The auditory 
system is basically suited to processing noises and music. For words to get their "meaning" further associations must occur. In the blind it is through somatosensation. In sighted persons, vision plays a predominant role and sounds of words form prominent associations with visual stimuli - for example, the spoken sound pencil is linked in some way with the visual pencil. If what has been presented is valid, vision and somatosensation are especially coupled, and the sound of a word would become associated with that coupling. Moreover, a meaningful association would occur only after each pattern is completed. Association, while patterns are being formed would yield chaos rather than meaning. The naming of an object seen or felt or the comprehension of a name would therefore involve widespread activity in the association cortex of all three modalities - visual, auditory and somesthetic. It is likely therefore that every mental Iransaction involves much or all of the association cortex. Just as the same receptor cells of the retina subserve many different incoming stimuli but in varied patterns, it is assumed that the same cells of the association cortex subserve many functions again utilizing many different patterns. In a very simple way we have as it were mapped the geography of the neural basis of the mind. Reading and writing are engrafted but they have been omitted for the sake of simplicity. For some 25 years 1 have used the lessons derived from the congenital cataract cases, in the interpretation of behavioral abnormalities associated with brain disease, and have found them most useful.

Once these visuo-auditory-somatosensory associations are established in early life, are the same neuronal patterns utilized permanently for this purpose or does short-circuiting or by-passing occur through habitual use, with some associations being dispensed with? This is an important question. Once a pencil is seen utilizing specific neuronal pathways, are all the same original patterns essential thereafter for the seeing of a pencil? The occurrence of visual agnosia in bi-parietal lesions would suggest the answer is yes. Short-circuiting does not occur.

\section{Ideation}

The complexity of the neuronal activity of the brain presents an impenetrable barrier to the clinician endeavoring to fathom the mind. External stimuli of each modality (visual, auditory, somesthetic, etc, enter the nervous system via their receptors and are transduced into electrochemical impulses that travel up to $100 \mathrm{~m}$ per sec. The cerebral cortex is estimated to have 10 billion neurons, each capable of firing hundreds of times per sec, and each having numerous branchings and thousands of synapses. The lightning speed and exquisite fineness of neuronal transactions are beyond the imagination.

The means by which electrical impulses in a nerve net create sensation, images and thoughts that constitute an individual's mind remain as mysterious as ever. These fundament matters can only be touched on here. There is predominant agreement among scientists that neuronal activity and the mind are one and the same thing. Lord Adrian and Sir Charles Symonds represent neurology in that view. ${ }^{8}$ The brain is a machine. In disagreement, Wilder Penfield ${ }^{8}$ and Sir John Eccles ${ }^{9}$ and even Sir Charles Sherrington, ${ }^{9}$ after wrestling with the problem all their lives were not convinced and believed that an immaterial extraneural energy, perhaps the spirit, stands above the neural network. According to this doctrine (dualism) the external world is reality and is defined in terms of physics and energy. The inter- nal world is the mind and consists of a special form of energy. Hughling Jackson' spoke of concomitance or psycho-physical parallelism indicating that for every mental state there is a neuronal state, neither interfering with the other. Bunge ${ }^{10}$ favors the terms psychoneural identity or psychoneural monism or emergent materialism.

The problem of brain-mind interface can perhaps be expressed in terms of somatosensation. The pressure of a finger on an animal's paw causes him to turn his head in that direction. If the animal had language he would say he had been touched. A touch in the periphery causes a change in the paw region of the animal's cortex, a change that is felt. Thus is created a small focus of mind. What is the feeling of touch when there is no language? The mind is largely the creation of language, as the mindlessness of a person with receptive aphasia eloquently testifies. Conceivably sentience, innate even in primitive brains, originates in somesthesia, where "I" resides.

In humans incoming stimuli from each of the sensory modalities, color, sound, somatosensation, give rise to corresponding cortical activity that replicates or represents external events. This cortical activity is referred to the outside, not to the brain. The inter-association of the cortical traces of the three modalities constitutes the more complex mind, just as did on a very small scale, the result of pressure on the animal's paw causing him to turn his head. Because of the paramount importance of language in humans it could be claimed that the theater of the mind will occupy mainly the speech area of the dominant hemisphere, the posterior temporal, inferior parietal and anterior occipital lobes.

The cortical activity and corresponding mind produced by incoming stimuli might be termed the exterogenic mind. What happens when there are no incoming stimuli? There is the common impression that the mind continues to exist in the form of thinking, pondering, mulling, wondering, etc. Introspection reveals that thinking takes the form of faint replicas of what has been seen, heard and felt in the past. This might be termed the interogenic mind. Thinking is the correct designation but since the word thinking is commonly used in different ways, as in solving a problem, considering a topic logically, weighing decisions, teaching children to think, etc. I prefer the term ideation for our thoughts and the associated feelings generated in the absence of obvious incoming stimuli. Ideation was the term used by Jackson.'

Ideation (or thinking) consists of an incessant ever-changing rapid stream of faint visual images, faint sounds of words and faint feelings. Internal language is agrammatical, telegraphic and pictorial, often taking an interrogative, conditional or subjunctive form. Names are not prominent for frequently the word to express an exact meaning has to be specially sought. Ideas follow one another automatically in rapid succession according to the rules of association as in "that reminds me". It is difficult to define whole thoughts or units of thought in terms of their duration, length and frequency but a few per second seems to be representative, at least on some occasions. The continuous mental experience derived from incoming stimuli and from ideation constitutes the stream of consciousness of James."

\section{The Unconscious}

We have considered the brain activity that occurs while the brain is receiving stimuli from the outside and also while it is 
ideating or thinking. What does the brain do when it is neither receiving nor ideating? Introspection suggests that normally there is no such state as not thinking. The brain when awake is constantly engaged in receiving or ideating; it is constantly occupied with highest level mental activity. At least that is the evidence from introspection. It was previously argued that each mental transaction utilizes all or most of the sensory association area on the dominant side of the brain. Is there any place in the brain for unconscious mental activity, that is unconscious, complex, ongoing ideation as in Freudian theory? ${ }^{12}$ The ideation postulated by Freud would indeed be complex since it presumably subserves desires and fantasy. What might be the neural substrate for such activity and when could it occur? The only system of association cortex is already constantly in action. Could two or more lines of thought simultaneously occupy the association cortex, one conscious, the other unconscious? It is not easily believable. In temporal lobe epilepsy the ideation of an aura is promptly recognized as an abnormal intrusion. The same is true of the visual aura of migraine. Two different lines of ideation become manifest to the individual. In persons with so-called multiple personalities, the states occur seriatim, not simultaneously. According to the present line of reasoning, the doctrine of an ever present unconscious mental activity subserving the struggle between id, superego and ego, determining the content of dreams, causing slips of the tongue and the forgetting of names is without foundation. There is no available association cortex that could sustain it. Freudian doctrine has been widely criticized on several grounds; the present critique is buttressed by the testimony of neurology.

This discussion of ideation makes it clear that brain function defines the individual. Each of us is the product of a constant furious electrochemical activity proceeding millisec by millsec, minute by minute, year by year for a lifetime, either mirroring the stimuli of the external world in unending combinations or creating ideation and thought. This activity produces the impression of a steady, relatively stable state which is the mind. It feels things, it sees things, it hears things. Moreover it knows it does these thing and talks about it. The mind is the ideation sustained by the association areas particularly in the left hemisphere where language resides. The nondominant hemisphere is largely dispensable, as is the motor strip. If "I" is defined by mind, "I" must be identified with the posterior temporal and parietal regions of the dominant hemisphere. It is here that the sentient "I", the authoritative "I", the controller, resides. Nearby is the dominant hippocampal system whose nonspecific associations account for memory. The remainder of the brain provides a service or regulatory function.

\section{VOLITION}

A discussion of the human mind would be regrettably deficient without an examination of what is known as volition or the will. Although James" stated that the question of free will is insoluble on psychological grounds, it could be an instructive exercise to examine the pros and cons from the standpoint of a neurologist.

My initial interest in the subject arose one day when contemplating Copernicus' simple earth shaking recognition that the sun does not really rise and set despite the universal impression of all earth-dwellers that it does. There came to mind the ques- tion: Does the neurology of behavior harbor any comparable illusion for mankind? Therewith the possibility presented itself that the impression that each of us has that our brain function is under voluntary control might also be an illusion. Could it be that our activities are under the dictates of the brain automatically, involuntarily without the control of volition, without the will, without "I" making decisions? How are we to know?

It was in this way that I, personally, was led to this subject which has been under philosophical debate since early Greek civilization, and continues today. In general psychologists and philosophers, for example, Ryle, say the will is a figment. ${ }^{13}$ Lord Adrian $^{8}$ the great neurophysiologist, was inclined to agree. Freud $^{12}$ wrote that there is within us a deeply rooted belief in psychic freedom and choice, that this belief is quite unscientific and must give ground before the claims of determinism that govern mental life. Penfield ${ }^{8}$ and Ecclese ${ }^{9}$ however sirongly favor the operation of a will. Is the nervous system an electrochemical machine whose course of action is determined by genomic constitution, training, experience and the present environment? Who is to decide? How can we know the answer? Does it make any difference which side is correct? The neurologist with his special knowledge should have an opinion, or at least should be interested.

A willed movement might arbitrarily be divided into two parts: a) the actual movement and b) the preceding decision to move the part, that is the thought or ideation preceding the movement. If we first consider the actual movement, it must be realized that even the simplest act entails the serial discharge in orderly fashion of hundreds of thousands of cells in the brain, spinal cord and muscles, integrating precentral, kinesthetic, cerebellar, striatal and visual impulses. It is inconceivable that deliberate intent or serial willing in the form of ideation could operate millisecond by millisecond to control serial successive micromovements. This is all beyond micromanagement.

Walking which seems to be automatic is said to involve the participation of almost all large and medium-sized muscles of the body. In our ordinary activities, all day long, a person is not aware of the movements of the limbs. It is surprising how much of our daily activity falls under the rubric of habit. We do not think about it. We are not even able to describe the every day movements we make daily, for example in putting on a coat, buttoning, rising from a bed, towelling after bathing, tying a bow, braking the car, etc. In fact attention to motor activity may impair performance. A concert pianist, while playing, dare not think about the movements his fingers are making. Where is the will? While a skilled act may unfold automatically there remains the question of whether the will was active in the decision to perform the act in the first place. This point will be addressed a little later.

In addition to the classical involuntary movement disorders of the neurological clinic there are many others that seem nonvolitional: tics, stuttering, writer's cramp, nail-biting, nail-picking, coprolalia, etc. Adults display various automatisms: crossing the knees, placing the arms akimbo, fidgetiness, scratching, touching the face, adjusting the hair, tossing the head, tapping the fingers or the foot, etc.

An impressive example of a complex motor act that approached the involuntary was portrayed by the baseball player, Ted Williams, standing at the plate with the baseball speeding towards him at $94 \mathrm{mph}$. Suddenly there occurred an 
explosion of motion as another homerun was chalked up. How much was voluntary?

Several years ago a stage performer demonstrated his ability to repeat what was being said to him, with so little delay the speaker was inhibited just as he would be when hearing his slightly delayed voice on radio. The performer said he was able to allow the speaker's voice to drive his own voice. Some intelligent persons unknowingly move their lips when another person is speaking to them or they mimic the facial expressions of the speaker.

Hypnotized subjects act involuntarily according to their own accounts. A striking example of impressed behavior is the occurrence of mass hysteria in normal school children afflicted with a fancied illness. Certainly it is not difficult to list instances in which activity seems not to have a volitional basis.

It is in the field of mental disorders however that behavior often seems particularly uncontrolled rather than voluntary and rational. A patient may cringe with fear before an auditory hallucination, kill an infant because a voice was heard, enthusiastically buy $\$ 100$ worth of penny candy, torture himself with paranoid thoughts about his wife's infidelity, act as if he has untold wealth, shoot a president to prove a lover's devotion, claim radio waves are influencing his mind, insist his arm is made of glass, check the gas cocks repeatedly whenever leaving the house, wash the hands repeatedly all day long lest they be contaminated, run panic stricken to get fresh air, jump from a tall building and so on. Do such unfortunate people decide of their own free will to act as they do? It might be said that such actions reflect mental aberration and are beyond volition, that they are of a different order than actions in normal persons. To claim different rules under the two circumstances introduces the insurmountable difficulty of determining where in the spectrum of behavior the will becomes operative. This would be an example of the principle of discontinuity ${ }^{14}$ whereby a qualitative innovation or new property emerges at some point along a continuum of change. A preferable alternative would be to say that abnormal behavior reflects aberrant ideation just a normal behavior reflects normal ideation.

Similarly in senile dementia, the patient may make rude remarks, neglect his personal toilet, balk when it is bath time. become angry when interrupted in one of his activities or fear being alone. The patient is childish. The will we would say is in abeyance, as if some special faculty had departed. But the same objection holds.

The complex ideation of dreams is devoid of volition. In delirium the patient's mental state may fluctuate between clarity and agitated confusion in a matter of minutes. Can the will come and go so readily?

It is likely that the actions of an infant or child under the age of seven years proceed automatically without cogitation or decision. The child learns the speech of his attendants, even the regional accent, apparently without effort. Children tend to mimic or copy one another. If there was no will in early life and one appears later when did the transition occur? This would be another example of discontinuity, a proposition that usually cannot be substantiated and is better avoided.

An interesting point concerning volition is raised by the ability of a dog to become house broken. A child in the same circumstances is said to be exercising voluntary control. Should it be said that the dog also is exerting his will? Using different cri- teria for neuronal activity in human and animal, requires the acquisition of a new property or capability, this time through phylogeny, still another example of discontinuity. This touches on the broad matter of whether animals have minds. There is widespread affirmative agreement on this point. ${ }^{15}$ This would be consonant with the present thesis that where there is a cortical conjunction of somesthetic, visual and auditory stimuli there is a mind. Again, sentience is held to arise in somesthesia.

A few further instances of a negative kind concerning free will must suffice although many more could be offered. We are not able to will ourselves to sleep; or to laugh. When we are worried we cannot deliberately think of other matters. We cannot control our thoughts. We seem unable to direct our flow of ideation. Many are unable to mend their drinking and eating habits. If there is a will, it must be flimsy judging from the commonplace of deceit and dishonesty in principled persons. The inefficacy of New Years's resolutions attests to this.

The foregoing account of actions seeming to occur automatically need not mean, however, that a deliberate act cannot be willed. It was proposed earlier that the flow of ideation is automatic and beyond the will. If action issues from ideation, it would follow that action also must be automatic or non-volitional.

If there be no free will, what determines our more deliberate actions? That is not easily answered. It is commonly postulated that choice is the product of an individual's thousands of previous experiences and the balance between favorable (positive) and unfavorable (negative) feelings about each pending choice. There is a pervasive feeling of do or do not. Skinner's theory of operant conditioning is exemplified. Skinner ${ }^{14}$ it should be noted, dropped the notion of the doctrine of free will as inner causal agent. The emotion associated with routine, everyday decision making must be very faint as it usually escapes our notice; only rarely is it agonizing.

Are there then no positive examples of the human will in action? James jested that getting out of a warm bed on a cold winter morning must indicate operation of the will." Seriously, as evidence of the will in behavior he cited the heroic effort required by individuals to maintain themselves virtuous and worthy in the face of evil temptation. According to James, decisions are the result of the ratio of forces pro and con. It would still be incumbent on him to demonstrate that the forces were willed rather than automatic. We are back to the irresolvable central argument. It is difficult to discover positive evidence of a separate and special function of the mind that can be called the faculty of volition. If there were, where would it reside? The complexity of the underlying ideation suggests that much of the ideating brain is involved.

\section{The Implications}

Were the doctrine of automaticity accepted what would the implication be? Without our sense of rugged individualism, personal responsibility, self-worth and free will, would not the human condition be demeaned. Would we not lack human dignity, pride and morale when told we no longer are masters of our souls? I think not. On balance it would make little or no difference. We would continue to have the same illusion we now have. The genesis of our behavior is so situated within our minds that we shall continue to have the undeniable impression that each of us is in charge of our person. Our actions always seem to issue from ourselves. A sense of involuntary does not exist. 
It must be appreciated that the physico-chemical machine model, by no means implies predestination. James ${ }^{11}$ in speaking of the human automaton implied that behavior would proceed automatically uninfluenced by and not influencing the mind. That is by no means the implication of the present thesis in which the mental and emotional determinants of behavior are paramount. Our minds and our behavior are still subject to all the influences of early training and the environment, that they have been in the past. Our potential remains unchanged. In the exposure to our surround, behavior may be altered and the mind modified intellectually or emotionally or both. A person cannot change by himself. The influence must come from outside: family, teacher, pastor, etc.

It could well make a difference however to neurologists in their approach to the problems of the individual. It would drive home the lesson of "just as the twig is bent". In the teaching and training of children it makes a difference that we not attribute volitional propensity to the child as the explanation for inadequacies such as aberrant behavior, disobedience, truancy, lack of motivation, failure to concentrate or pay attention, etc. The prevention of bad habits becomes crucial if "willing" is incapable of correcting them.

In behavioral neurology it may be advantageous to regard abnormal states and actions as unfolding in the absence of a will, as though the patient were an automaton. The idea is contained in the adage that the patient is always doing the best he can. It seems to be second nature for clinicians to attribute behavioral vagaries to a patient's willfulness or to some psychological quirk - he's not trying, he doesn't want to get well, he's obstinate and so on. By avoiding such false interpretations our management of patients should be more logical as we devise ways of altering their behavior for the good. In the interpretation of aphasia, agnosia and apraxia it can be instructive for the physician to proceed on the basis that the patient is a human automaton.

In mental illness interpretation can be pursued to advantage under the doctrine of automaticity - obsessive compulsive neurosis, agoraphobia, depression, schizophrenia, paranoia, autism, habituation to tobacco, alcohol and drugs, obesity, bulimia, anorexia, compulsive gambling, insomnia, kleptomania, etc. The same is true of lying, dishonesty, fudging in science and illegal and criminal behaviour. Hysteria and litigation neurosis are special instances. The list goes on. How we think about these conditions will determine our therapeutic approach.

Anosognosia (unawareness, lack of insight) accompanies a great number of neurological disturbances in the ideational system - non-dominant sensorimotor deficit involving the parietal lobe, amnesia, fluent aphasia, apraxia, abulia, cortical blindness, some hemianopias, confusion, etc. On the other hand, patients as a rule become aware of motor deficits, paresthesias, anxiety and depression. Ideation appears to run automatically without awareness of defects within its own system.

\section{The EMOTIONS}

It was proposed earlier that an emotional feeling of some kind accompanies or participates in all ideation, decision-making and action. In routine activity the feeling is faint or inobvious. Evidence of its presence is the fact that in severe depression or in the advanced apathy of abulia, the patient is often reduced to silent catatonic immobility. Despite their central importance in human endeavor knowledge of the emotions is still rather limited be it definition, classification, origin, physiology, expression or locus of participation in the mind.

In the period since the James-Lange theory of the peripheral origin of the emotions fell into disfavor, no other convincing formulation has risen to take its place. From the field of temporal lobe epilepsy has come the observation that auras arising in the region of the amygdala can be associated with fear, depression, paranoia, euphoria and rarely ecstasy ${ }^{16.17}$ (and personal observations). To deny any role at all for the periphery (somatosensory, autonomic) would mean that the emotions are a primary cortical sensation like other sensory modalities but without being referred to the periphery. Common experience indicates however that the periphery does in fact participate (grief, laughter and crying for example in the territory of the cranial nerves) and this calls for rehabilitation of the JamesLange theory. In the same vein, where is the site of worry, depression, happiness? These comments illustrate that even the theatre of the emotions has still to be established.

Although animals present a considerable repertoire of emotions $^{18}$ it is only in humans that emotions can be properly studied. The effect of neurological disease on the emotions and their expression, offers a fruitful field for investigation, as exemplified in the observations of pseudobulbar pathological laughing and crying. ${ }^{19}$ The stimulation and ablation studies of various areas of the brain, in particular the amygdala ${ }^{20}$ and the occurrence of depression in strokes ${ }^{21}$ are other examples. There are innumerable unexplored opportunities for more clearly focussing on the nature and mechanism of the emotions as revealed in neurological disease. What is the emotional spectrum of patients in the locked-in syndrome, the total paralysis of the Guillain-Barré syndrome, cervical quadriplegia, advanced parkinsonism, the non-dominant parietal lobe syndrome, bilateral facial sensory loss and so on? Is the crying of an anencephalic neonate normal or that of a neonate with Werdnig-Hoffman paralysis? What does it mean that suicidally depressed patients tend to have pleasant dreams? ${ }^{22}$ Still other instances come to mind: the irascible aphasiac, the agitated uncooperative patient, agoraphobic victims? The introduction of MR imaging has greatly facilitated study of the effect of focal cerebral lesions on mental states. Also rapid $\mathrm{MRI}^{23}$ will assist in detecting focal physiological changes.

It is with this vista of promise that I close this essay about the mind from the perspective of a neurologist. It does not delve into neurophysiology, nor does it enter the field of philosophy or logic. It presents what might be called a common-sense clinicoanatomic model, which to be sure, carries no special prospect of being correct. There has been no mention of consciousness, intentionality or cognition. The use of metaphor, analogy and complex adjectives has been held to a minimum.

\section{ACKNOWLEDGEMENT}

This study was generously supported by an award from the Mihara Memorial Foundation, Tokyo.

\section{REFERENCES}

1. Jackson HJ. In: Taylor J, Holmes G, Walshe FMR, eds. Selected Writings. New York: Basic Books Inc. 1958; Vol 2: 72, 265. 
2. von Senden M. Space and Sight. Translated by Heath P, Glencoe, Illinois. The Free Press 1960; 309.

3. Fisher CM. The late acquisition of vision by persons born blind as a result of bilateral congenital cataracts. Trans Amer Neurol Assoc 1964; 89: 195-197.

4. Riesen AH. The development of visual perception in man and chimpanzee. Science 1947; 106: 107-108.

5. Diderot D. Lettre sur les aveugles à l'usage de ceux que voient. Paris; Durand 1749: 54.

6. Condillac EB. Traité des Sensations. Paris 1778; 46, 131.

7. Keller H. The Story of my Life. New York: Buccaneer Books 1976; 36.

8. Penfield WG. The Mystery of the Mind. Princeton: University Press $1975 ; 89,91$.

9. Eccles JC. The human psyche. Heidelberg: Springer International 1980; 30, 240, 243.

10. Bunge M. Emergence and the mind. Neuroscience $1977 ; 2: 501-$ 509.

11. James W. In: Myers GE, ed. Writings 1878-1899. Literary Classics of the United States Inc. New York, NY 1992; 152, 395, 423, 425.

12. Freud S. A general introduction to psychoanalysis. English translation by Riviere J. Garden City, NY: Permabooks 1956; 112.

13. Ryle G. The concept of mind. London: Hutchinson \& Co. 1949; 62.

14. Skinner BF. Science and human behavior. New York: Macmillan $1953 ; 38,116$.
15. Mackintosh N. Animal Minds. In: Blakemore C, Greenfield S, eds. Mindwaves. Oxford: Basil Blackwell Lid. 1987; 55-72.

16. Penfield WG, Jasper H. Epilepsy and the functional anatomy of the human brain. Boston: Little Brown 1954; 447.

17. Williams D. The structure of emotions reflected in epileptic experiences. Brain 1956; 79: 29-67.

18. Darwin C. The expression of emotions in man and animals. New York: Appleton 1929.

19. Poeck K. Pathological laughing and crying. In: Vinken PJ, Bruyn GW, Klawans HV, eds. Handbook of Clinical Neurology. Amsterdam: North Holland 1985; 45: 219.

20. Narabayashi $H$, Nagao T, Saito $Y$, Yoshida $M$, Nagahata $M$. Stereotaxic amygdalectomy for behavioral disorders. Arch Neurol 1963; 9: 1-16.

21. Robinson RG, Kubos KL, Starr LB, Rao K, Price TR. Mood disorders in stroke patients: importance of location of lesion. Brain 1984; 107: 81-93.

22. Miller JB. Dreams during various stages of depression. Arch Gen Psychiat 1969; 20: 560-565.

23. Belliveau JW, Kennedy DN, McKinstry RC, et al. Functional mapping of the human visual cortex by magnetic resonance imaging. Science 1991; 254: 716-719. 